\title{
Practical ways to deal with the high burden of cardiovascular disease in hemodialysis patients
}

\author{
Instituto do Coração (InCor), Faculdade de Medicina da Universidade de \\ São Paulo, São Paulo, Brazil
}

\section{ABSTRACT}

Cardiovascular disease is the main cause of death among hemodialysis patients. Although uremia by itself may be considered to be a cardiovascular risk factor, a significant proportion of dialysis patients die because of cardiovascular disease not directly attributable to uremia. Indeed, many of the cardiovascular diseases and cardiovascular risk factors in these patients are common to those occurring in the general population and are amenable to intervention. Lack of proper medical care during the early stages of renal insufficiency and present-day dialysis routines, by failing to correct hypertension, hypervolemia and left ventricular hypertrophy in many patients, may also add to the cardiovascular burden. The author suggests that, in addition to early treatment and referral to a specialist, chronic renal failure patients should undergo intensive cardiovascular screening and treatment, and correction of cardiovascular risk factors based on guidelines established for the general population.

KEY WORDS: Renal dialysis. Chronic kidney failure. Cardiovascular diseases. Risk. Uremia. Diagnosis.
INTRDDUCTION

Cardiovascular disease (CVD) is prevalent in patients with renal failure and accounts for $50 \%$ of all dialysis deaths. ${ }^{1}$ Raw (nonadjusted) mortality rates in industrialized countries during the first year on hemodialysis range from roughly $10 \%$ in Western Europe and Japan to $20 \%$ in the United States. ${ }^{1,2}$ The corresponding figure in Brazil is $18 \% .^{2}$ Estimates from different countries indicate that more than $60 \%$ of patients die before completing 10 years on dialysis. ${ }^{3}$ This high mortality rate is at least in part caused by the extraordinarily high frequency of cardiovascular risk factors and established CVD that are present in a significant proportion of these patients. However, a close look at the extensive list of cardiovascular risk factors and CVD associated with chronic uremia shows that many risk factors are preventable or amenable to control or attenuation by appropriate therapeutic interventions. The author therefore hypothesizes that the high morbidity and mortality rates observed among kidney failure patients might, in some cases, be a consequence of underdiagnosis and underutilization of interventions that have proven useful among the general population for preventing and treating CVD. The author also believes that dialysis, in the way it is performed nowadays, may contribute towards mortality by failing to correct for or prevent important cardiovascular risk factors.

The present discussion makes use of information from the literature and from personal experience to suggest some practical ways for preventing and reducing cardiovascular complications due to dialysis. The personal contribution is based on data from observations of two populations of hemodialysis patients followed up at the author's institution during the last 10 years: a low-risk group of 120 relatively young patients with low prevalence of comorbidity and a high-risk cohort of 335 subjects who were at least 50 years old and presented diabetes or clinically evident CVD, or both of these (Table 1$).{ }^{4-7}$

\section{IDENTIFICATION QF HIGH-RIBK HEMODIALYBIB PATIENTE}

Prompt identification of high-risk patients will result in more successful interventions. This is accomplished by identifying individuals with established CVD or those at risk of developing CVD, and calculating the probability of developing cardiovascular events in the future. Among the general population, the latter is usually achieved by applying equations derived from prospective studies in large groups of individuals who were followed up for long periods of time, as described below.

\section{CARDIOVABCULAR RIBK FACTORE}

\section{TRADITIONAL LARDIDVASELLAR} RISK FALTORS

Among the general population, cardiovascular risk is usually calculated using the Framingham equations. ${ }^{8}$ These equations should be applied only to individuals without overt cardiovascular target organ damage because, in such cases, by definition, the cardiovascular risk is already greater than $20 \%$ over a tenyear period, while a $20 \%$ event probability per decade is arbitrarily used to define highrisk status. Variables used in these equations include age, sex, diabetic and smoking status, total and high-density lipoprotein-cholesterol (HDL-cholesterol) and systolic and diastolic blood pressure. Because of the high rate of established cardiovascular disease in end-stage kidney failure, the Framingham equations are considered to be of limited use for calculating the probability of events for the whole population of dialysis patients. ${ }^{9,10}$

The Choice Study ${ }^{11}$ found that the projected five-year cardiovascular risk based on the Framingham Risk Equation was 13\% 
among dialysis patients over 40 years old without overt cardiovascular disease and was $6 \%$ among the controls matched for age, sex and race. Cheung et al. ${ }^{12}$ reported no significant difference between the calculated cardiovascular risk among low-risk dialysis patients and age-matched controls.

The present author's group compared the absolute and relative 10-year cardiovascular risks among 123 hemodialysis patients, who had an $86 \%$ prevalence of hypertension, with those among an age-matched group of essentially hypertensive subjects who were also followed up at the author's institution. The absolute risk did not differ between the groups and was close to $15 \%$, whereas the relative risk was twice as high as among the low-risk Framingham control population. ${ }^{13}$ In the study by the present author's group, $20 \%$ of the dialysis patients and $19 \%$ of the hypertensive patients presented a risk of more than $20 \%$ per decade of life that they would have the event. ${ }^{13}$ Because the cardiovascular risk in the nonselected dialysis population is 10 to 15 times higher than in the general population, ${ }^{14}$ these results have been interpreted as an indication that the Framingham equations explain only a small part of the extraordinarily high cardiovascular risk among end-stage kidney failure patients. ${ }^{11,15}$

In fact, it seems likely that the patients classified as low-risk may have occult CVD that will become manifest in the future. In agreement with this view, the present author's group observed that $30 \%$ of their dialysis patients included in the abovementioned analysis of Framingham Risk Equations presented $\geq 70 \%$ coronary stenosis in one or more coronary arteries, in spite of the absence of clinical evidence of coronary artery disease (CAD). ${ }^{13}$ Alternatively, it is also possible that some dialysis patients without overt cardiovascular disease are indeed at relatively low risk of developing cardiovascular complications. Prospective studies are necessary to determine whether this relatively low risk will be confirmed by a comparable low prevalence of events in the future.

\section{NONTRADITIONAL}

\section{GARDIOVABCULAR RIBK FACTORE}

Because the classical risk factors included in the Framingham equations fall short in explaining the high prevalence of cardiovascular events among dialysis patients, there has been speculation that this occurs because some alterations that are peculiar to the uremic syndrome are not included in the risk calculations. ${ }^{10}$ Anemia, chronic hypervolemia, un- derdialysis, abnormal calcium and phosphate metabolism, hyperhomocysteinemia, high lipoprotein(A), oxidative stress and low-grade inflammation could significantly contribute towards the cardiovascular damage in kidney failure. However, except perhaps for anemia, hypervolemia and altered calcium-phosphate metabolism, evidence linking these factors to the prognosis is still fragmentary, and so far this evidence has not been integrated into one comprehensive equation.

\section{ESTABLIBHED CARDIDVABCULAR DIBEABEB}

Probably more important than traditional and nontraditional cardiovascular risk factors in determining outcomes for dialysis patients is the existence of established cardiovascular disease. In one large study, ${ }^{15}$ at least half of all the patients starting on dialysis had overt CVD. A history of cardiac failure was present in $35 \%$, coronary disease in $32 \%$, peripheral vascular disease in $17 \%$ and cerebrovascular disease in $10 \%$ of the cases. Also, left ventricular (LV) hypertrophy, as assessed by echocardiography, attained a frequency close to $80 \%$. In the patient series with prevalent high risk studied by the present author's group (Table 1), 43\% had clinical evidence of at least one CVD: heart failure, 9\%; peripheral vascular disease, 28\%; previous stroke, $9 \%$; history of myocardial infarction, $10 \%$; and history of myocardial revascularization, $4 \%$. LV hypertrophy was observed in 94\%. It was also found that the presence of established CVD had a clear impact on the prognosis.
After a mean follow-up of six years, the patients with evidence of CVD at the inception had four times more chance of developing cardiovascular events.

\section{LATE REFERRAL FOR DIALYGIS}

Patients starting on dialysis without previous medical care have a higher frequency of early death (within one year), ${ }^{16}$ reduced overall survival, ${ }^{17}$ excessive morbidity, ${ }^{18}$ and poorer quality of life. ${ }^{19}$ This is not surprising, considering that many disorders, including CVD, are already present in many patients, from the earliest stages of renal insufficiency. According to Sesso and Belasco, ${ }^{17} 58 \%$ of the patients admitted to a maintenance dialysis program in Brazil had a late diagnosis. In the present author's group of 335 high-risk patients, 32\% of the cases had their diagnosis of renal failure established less than 60 days before starting on dialysis, and only $5 \%$ of these patients had access to nephrologists before reaching the final stages of their disease. Lack of proper medical care not only contributes towards accelerating the progression of the renal disease, but it also leaves unchecked many cardiovascular risk factors. Therefore, early diagnosis of kidney failure and referral to a nephrologist may have a significant impact on reducing the CVD burden of these patients.

\section{UNDERDIALYGIS}

Ideally, good renal replacement therapy would perform like a normal kidney, keeping metabolic and hemodynamic parameters close to normal. If this concept is accepted, it follows

Table 1. Characteristics of low and high-risk hemodialysis patients followed up at Instituto do Coração (InCor) ${ }^{4.7}$

\begin{tabular}{lcc}
\hline Characteristics & Low-risk & High-risk \\
\hline $\mathbf{n}$ & 103 & 335 \\
Follow-up range (months) & $6-120$ & $2-84$ \\
Time on dialysis (months) & 30 (median) & 38 (median) \\
Age (years) & $44 \pm 13$ & $56 \pm 8$ \\
Males & $50 \%$ & $72 \%$ \\
Whites & $73 \%$ & $66 \%$ \\
Smoking & $17 \%$ & $27 \%$ \\
Diabetes & $3 \%$ & $37 \%$ \\
Dyslipidemia & $28 \%$ & $43 \%$ \\
Hypertension & $36 \%$ & $86 \%$ \\
Myocardial infarction & $0 \%$ & $10 \%$ \\
Myocardial revascularization & $0 \%$ & $4 \%$ \\
Stroke & $0 \%$ & $9 \%$ \\
Vasculopathy & $0 \%$ & $28 \%$ \\
Heart failure & $0 \%$ & $9 \%$ \\
CAD (stenosis $>$ 70\%) & Not determined & $43 \%$ \\
LV hypertrophy & $75 \%$ & $94 \%$ \\
\hline
\end{tabular}

$C A D=$ coronary artery disease; $L V=$ left ventricular 
that all types of dialysis presently in use provide underdialysis. In fact, many patients dialyzed according to state-of-the-art dialysis techniques are hypertensive and only infrequently achieve a sustained state of euvolemia. ${ }^{20}$ It is therefore conceivable that complications and mortality due to dialysis are related to insufficient and, sometimes, substandard substitutive renal function. Evidence supporting this view is provided by data showing that survival on dialysis is proportional to the dialysis dosage, which is usually calculated in terms of hours of dialysis delivered per week or month or by the fractional clearance of urea $(\mathrm{KT} / \mathrm{V})$. $^{21,22}$

Treatment with fewer hours of dialysis than the minimum 12 hours per week recommended is accompanied by higher mortality rates. ${ }^{23}$ For example, a retrospective European study, ${ }^{23}$ including more than 70,000 patients, showed that the gross mortality rate over one year was $8.3 \%$ for patients dialyzed for at least 12 hours per week and $11.8 \%$ for those dialyzed for 9 to 11 hours per week.

Thus far, the highest long-term hemodialysis survival rates have been reported by groups that use the largest doses and the longest times for dialysis. ${ }^{24}$ In this respect, the duration or frequency of dialysis sessions appears to correlate better with survival than with KT/V..$^{25-27}$ This could be expected, because adequate KT/V does not presuppose control of either hypertension or hypervolemia, among other variables influencing the prognosis. Although economic and logistic difficulties create limitations on the widespread use of longer dialysis times, at least it is important to provide an effective minimum of 12 hours per week, on dialysis schedules with adequate $\mathrm{KT} / \mathrm{V}$.

Over the past decade, new hemodialysis options have been introduced and old ones resuscitated with encouraging results, including daily short dialysis and nightly hemodialysis. These approaches appear to provide better control over blood pressure, nutritional state, bone metabolism and anemia than does the traditional method. ${ }^{28}$

\section{UNDERPRESCRIPTION QF \\ CARDIOPROTECTIVE DRUEG}

Because the probability of future cardiac events in patients with chronic renal disease surpasses $20 \%$ in ten years, kidney failure is now considered to be a "coronary heart disease equivalent. ${ }^{29}$ Angiotensin-converting enzyme inhibitors (or AT1 blockers), lowdose aspirin, beta blockers and statins reduce the incidence and severity of CVD, and their use is considered mandatory for high-risk patients. ${ }^{29}$ In practical terms, this means the routine prescription of the first three of these drug types for all dialysis patients, and statins for those with increased cholesterol levels. However, compelling evidence indicates that this practice is frequently overlooked. ${ }^{30-32}$ For instance, in one study, ${ }^{30}$ fewer than $50 \%$ of the chronic kidney failure patients received each type of agent, even when established CVD was present. Among the present author's high-risk group of hemodialysis patients, it was observed that $74 \%$ were taking none or only one of the four cardioprotective drug types. ${ }^{13}$ This situation was not altered when diabetic patients and those with CAD were analyzed separately.

\section{CORONARY ARTERY DISEABE}

The importance of CAD with regard to the prognosis for dialysis patients can hardly be exaggerated, because cardiac ischemic events are involved in $40 \%$ to $50 \%$ of all cardiovascular deaths in this population. ${ }^{9}$ Therefore, early identification and proper interventions will, very likely, have an important effect on the prognosis for patients with CAD. The reported proportions of dialysis patients with CAD varies in relation to many factors like age, diabetic status, length of follow-up and the diligence with which CAD is investigated. The angiographically confirmed prevalence of CAD with stenosis of more than $50 \%$ ranges from $24 \%$ among low-risk patients to $85 \%$ among older patients with diabetes. ${ }^{33}$ However, most of these estimates originated from studies in which angiography was performed only on patients with clinical evidence of CAD or whose noninvasive test results were suggestive of CAD.

Using coronary angiography, the present author's group studied 335 consecutive high-risk renal transplant candidates who were sent to their institution for preoperative evaluation, independently of the symptoms. Coronary stenosis $\geq 40 \%$ was found in $60 \%$ of the patients and $\geq 70 \%$ in $43 \%$. It was also observed that the patients' angina and noninvasive test results (myocardial scintigraphy and dobutamine-stress echocardiography) had a poor correlation with significant CAD. ${ }^{4}$ Moreover, the presence of stenosis $\geq 70 \%$ was the best predictor of cardiovascular events, in comparison with clinical stratification and noninvasive testing. After 48 months, the probability of event-free survival was $94 \%$ for patients with stenosis $<70 \%$ and $54 \%$ for those with stenosis $\geq 70 \%$. Patients with significant CAD had almost ten times higher relative risk of developing events than those with normal coronary arteries or less severe degrees of CAD. Both myocardial scintigraphy and stress echocardiography failed to identify roughly $30 \%$ of the patients who developed events. These results suggest that coronary angiography should be performed on all high-risk dialysis patients. We are presently evaluating whether noninvasive testing offers any advantage over clinical stratification among low-risk dialysis patients. Prospective large-scale studies are necessary to define the location for invasive coronary interventions among this population.

\section{DIABETEE}

Diabetes is highly prevalent among dialysis patients. Diabetes, age, and CAD are the most important factors influencing survival when on dialysis, and diabetic patients continue to do worse than nondiabetic patients on renal replacement therapy. ${ }^{26}$ Diabetes increases the incidence and severity of cardiac and extracardiac atherosclerosis and is frequently associated with malnutrition. Many centers perform coronary arteriography routinely on diabetic patients with end-stage renal disease prior to kidney transplantation. ${ }^{34}$ Thirty-seven percent of the high-risk patients studied by the present author's group had diabetes (Table 1). ${ }^{4-7}$ Among these patients, significant CAD was observed in $53 \%$, compared with a prevalence of $35 \%$ among nondiabetic patients $(\mathrm{p}<0.05)$. One reasonable speculation is that diabetic patients have more cardiovascular events because they present higher prevalence of CAD, but this may be only partially true. The present author's group observed that patients with diabetes without $\mathrm{CAD}$ presented a risk of developing major cardiovascular events that was similar to that of nondiabetic patients with CAD. ${ }^{5}$ Over a six-year period, the event-free survival rate was comparable between the two groups and less than $50 \%$ for both of them. On the other hand, subjects without either disease presented an event-free survival rate of close to $85 \%$ over the same observation period. These results indicate that diabetes confers a cardiovascular risk similar to that of $\mathrm{CAD}$ and points towards the need for intensive treatment of diabetes and its complications. They also suggest that coronary angiography should be performed on all diabetic patients undergoing dialysis, independently of symptoms and the possibility of kidney transplantation.

\section{HYPERTENBION}

Hypertension is probably the most frequent cardiovascular risk factor found among dialysis patients, but its prevalence is highly variable. In general terms, the prevalence of 
hypertension in nonselected dialysis populations is usually greater than $70 \% .{ }^{35}$ In a recent report by Agarwal et al. ${ }^{36}$ hypertension was documented in $86 \%$ of 2,535 patients and was adequately controlled in only $30 \%$. In the cohort of 335 high-risk patients studied by the present author's group, $86 \%$ were hypertensive and an additional 9\% were normotensive with the use of drugs at the initial evaluation. On the other hand, the prevalence of noncontrolled hypertension was $36 \%$ of 103 younger, low-risk subjects also studied by the present author ${ }^{37}$ (Table 1 ). It is worth mentioning that more than $90 \%$ of the patients with hypertension in both populations were taking antihypertensive medication. This high rate of treatment failure is likely to be influenced by a state of chronic hypervolemia, due to insufficient fluid removal by dialysis, as discussed above. Control of blood pressure through normalization of extracellular volume is feasible, but usually requires prolonged duration of dialysis or more frequent dialysis sessions. ${ }^{37}$ In addition, the present author's group has observed that nephrologists tend to tolerate some degree of hypertension in their patients, with the objective of reducing the episodes of hypotension induced by fluid removal during dialysis. ${ }^{37}$ All this results in blood pressure levels far above the recommended target level of $140 / 80 \mathrm{mmHg}$ for patients with chronic uremia. ${ }^{9}$ Hypertension might exert a number of negative effects, including left ventricular hypertrophy (LVH), heart failure and CAD. Therefore, adequate blood pressure control must be a major objective in the management of patients on dialysis. ${ }^{38}$ The present author's group found that systolic blood pressure was a strong predictor of complex arrhythmia, ${ }^{39}$ LVH and ventricular remodeling. ${ }^{37}$ Even more importantly, it was also observed that hypertension was associated with reduced long-term survival. The risk of dying was 2.2 times higher among hypertensive patients, and increased by $7 \%$ for each additional year of age and by $0.7 \%$ for each one-gram increase in the left ventricular mass index. ${ }^{37}$

\section{LEFT VENTRICULAR HYPERTROPHY}

Left ventricular hypertrophy $(\mathrm{LVH})$ is also highly prevalent and a major predictor of death among dialysis patients. ${ }^{37,40}$ The causes of LVH include age, hypertension, hypervolemia, anemia and arterial-venous fistula for dialysis access. LVH (defined as left ventricular mass index, LVMI > $125 \mathrm{~g} / \mathrm{m}^{2}$ ) was detected in $94 \%$ and $75 \%$ of the high and low-risk groups studied by the present author's group, respectively, and was influenced by systolic blood pressure and hematocrit level. ${ }^{41}$ In this study, concentric hypertrophy, which is associated with higher cardiovascular risk and target organ damage, in contrast with eccentric hypertrophy, ${ }^{42}$ was restricted to patients with previous or uncontrolled hypertension. In the subgroup of patients who had no past or present hypertension, $61 \%$ had normal ventricles, 9\% LV concentric remodeling and 30\% eccentric hypertrophy. ${ }^{41,43}$ Other studies have shown that regression of $\mathrm{LVH}$ in chronic kidney failure cases can be achieved with reduction in blood pressure. ${ }^{44,45}$ The present author's group also observed significant long-term reduction in LVMI with good blood pressure control after kidney transplantation. ${ }^{46}$

\section{LIPID METABDLIBM}

The serum lipid profiles of hemodialysis patients have been extensively studied and typically consist of normal or low total cholesterol and low-density lipoprotein cholesterol (LDL-C), low high-density lipoprotein cholesterol (HDL-C), and moderately increased triglycerides, $\mathrm{Lp}(\mathrm{a})$ and intermediate density lipoproteins. ${ }^{6}$ The prevalence of dyslipidemia is influenced by many factors, such as age, nutritional state, target population and comorbidity (especially diabetes). For instance, in the low and high-risk groups studied by the present author's group, the prevalence of dyslipidemia, defined as total cholesterol and/or triglycerides greater than $200 \mathrm{mg} / 100 \mathrm{ml}$, was $28 \%$ and $43 \%$, respectively (Table 1$)^{4-7}$ The role of dyslipidemia in relation to the cardiac risk of dialysis patients is unclear, because of the presence of multiple confounding factors and the paucity of prospective studies encompassing a large number of individuals. Also, no clear and definitive evidence exists regarding the beneficial effects of lipid-lowering agents on reducing cardiovascular complications. On the other hand, low total cholesterol levels are associated with increased overall and cardiovascular mortality when on dialysis, possibly as a reflection of malnutrition and inflammation. ${ }^{47}$ In spite of this, the present recommendations are to treat individuals with end-stage renal disease as presenting high cardiovascular risk, using the lipid targets for patients with atherosclerosis but no kidney disease. ${ }^{9}$ This means targeting the total cholesterol level at $<$ $200 \mathrm{mg} / 100 \mathrm{ml}$ and LDL-cholesterol at $<160$ $\mathrm{mg} / 100 \mathrm{ml}$, using drugs as needed. More stringent control of LDL-cholesterol is required for patients with manifest cardiovascular disease, as advised for the nonuremic population. As discussed above, many patients with dyslipidemia are not receiving cholesterol-lowering drugs, despite evidence that such drugs are safe for dialysis patients.

\section{MALNUTRITION}

Malnutrition is one of the most important causes of death when on dialysis ${ }^{7,48}$ and has been reported in as many as $36 \%$ of patients admitted for renal replacement therapy. ${ }^{49}$ Better nutritional status is related to prolonged survival. ${ }^{50,51}$ Malnutrition appears also to correlate with cardiovascular complications and cardiovascular death when on dialysis, although it is not clear whether this reflects a cause-effect relationship. What is evident is that malnutrition markers (low hematocrit levels and reduced serum creatinine, total cholesterol and albumin) and micro-inflammation frequently coexist and are closely related to high levels of atherogenic cardiovascular risk factors and cardiovascular death. ${ }^{52}$ Therefore, identification of patients with malnutrition will also reveal those at greater cardiovascular risk. Statins and angiotensin conversion enzyme (ACE) inhibitors have been shown to reduce $\mathrm{C}$-reactive protein, blood pressure and cholesterol in the general population ${ }^{53}$ but, as discussed above, these medications are not frequently prescribed to dialysis patients.

\section{CDNCLUSIONS}

Cardiovascular disease must be actively pursued and treated in all hemodialysis patients. CAD is of special concern because it is frequent, often asymptomatic and is a strong predictor of death. Patients without clinically apparent CVD should be considered to be at high risk and treated as such. All measures proven useful in the general population for preventing and reducing the risk of cardiovascular events must be used, including cardioprotective drugs. Patients with diabetes are particularly prone to events because diabetes entails a risk of events similar to what is associated with CAD. Chronic hypervolemia, hypertension and left ventricular hypertrophy are probably better treated or prevented by providing the best possible quality of dialysis or, even better, extending the duration or frequency of the dialysis sessions. These measures have the highest possibility of success when started during the initial stages of kidney failure, before starting dialysis. Early diagnosis and referral to a specialist are essential for achieving these goals. 
1. Sarnak MJ, Levey AS, Schoolwerth AC, et al. Kidney disease as a risk factor for development of cardiovascular disease: a statemen from the American Heart Association Councils on Kidney in Cardiovascular Disease, High Blood Pressure Research, Clinical Cardiology, and Epidemiology and Prevention. Circulation. 2003;108:2154-69

2. Zatz R, Romao JE Jr, Noronha IL. Nephrology in Latin America, with special emphasis on Brazil. Kidney Int Suppl. 2003;(83):S131-4.

3. Locatelli F, Del Vecchio L, Manzoni C. Morbidity and mortality on maintenance haemodialysis. Nephron. 1998;80(4):380-400.

4. De Lima JJ, Sabbaga E, Vieira ML, et al. Coronary angiography is the best predictor of events in renal transplant candidates compared with noninvasive testing. Hypertension. 2003;42(3):263-8

5. De Lima JJ, Gowdak LH, Vieira ML, de Paula FJ, Ramires JA, Krieger EM. Diabetes increases cardiovascular morbidity and mortality in patients with end-stage renal disease even in the absence of significant coronary artery disease. [Abstract] Circulation. 2003;108(17 Suppl):S719.

6. Kasiske BL. Hyperlipidemia in patients with chronic renal disease. Am J Kidney Dis. 1998;32(5 Suppl 3):S142-56.

7. De Lima JJ, Sesso R, Abensur H, et al. Predictors of mortality in long-term haemodialysis patients with a low prevalence of comorbid conditions. Nephrol Dial Transplant. 1995;10(9):1708-13.

8. Grundy SM, Pasternak R, Greenland P, Smith S Jr, Fuster V. AHA/ACC scientific statement: Assessment of cardiovascular risk by use of multiple-risk-factor assessment equations: a statement for healthcare professionals from the American Heart Association and the American College of Cardiology. J Am Coll Cardiol. 1999;34(4):1348-59.

9. Levey AS, Beto JA, Coronado BE, et al. Controlling the epidemic of cardiovascular disease in chronic renal disease: what do we know? What do we need to learn? Where do we go from here? National Kidney Foundation Task Force on Cardiovascular Disease. Am J Kidney Dis. 1998;32(5):853-906.

10. Covic A, Gusbeth-Tatomir P, Goldsmith DJ. The challenge of cardiovascular risk factors in end-stage renal disease. J Nephrol. 2003;16(4):476-86

11. Longenecker JC, Coresh J, Powe NR, et al. Traditional cardiovascular disease risk factors in dialysis patients compared with the general population: the CHOICE Study. J Am Soc Nephrol. 2002;13(7):1918-27.

12. Cheung AK, Sarnak MJ, Yan G, et al. Atherosclerotic cardiovascular disease risks in chronic hemodialysis patients. Kidney Int. 2000;58(1):353-62.

13. Gowdak LHW, Paula FJ, Giorgi DMA, Vieira MLC, Krieger EM, De Lima JJG. Doença cardiovascular e fatores de risco cardiovascular em candidatos a transplante renal. [Cardiovascular disease and risk factors in candidates for renal transplantation]. Arq Bras Cardiol. 2005;84(2):156-160.

14. Parfrey PS, Foley RN, Harnett JD, Kent GM, Murray D, Barre PE. Outcome and risk factors of ischemic heart disease in chronic uremia. Kidney Int. 1996;49(5):1428-34.

15. Foley RN. Clinical epidemiology of cardiac disease in dialysis patients: left ventricular hypertrophy, ischemic heart disease, and cardiac failure. Semin Dial. 2003;16(2):111-7.

16. Innes A, Rowe PA, Burden RP, Morgan AG. Early deaths on renal replacement therapy: the need for early nephrological referral. Nephrol Dial Transplant. 1992;7(6):467-71

17. Sesso R, Belasco AG. Late diagnosis of chronic renal failure and mortality on maintenance dialysis. Nephrol Dial Transplant. 1996;11(12):2417-20

18. Ifudu O, Dawood M, Homel P, Friedman EA. Excess morbidity in patients starting uremia therapy without prior care by a nephrologist. Am J Kidney Dis. 1996;28(6):841-5.
19. Sesso R, Yoshihiro MM, Ajzen H. Late diagnosis of chronic renal failure and the quality of life during dialysis treatment. Braz J Med Biol Res. 1996;29(10):1283-9.

20. Berthoux F, Jones E, Gellert R, Mendel S, Saker L, Briggs D. Epidemiological data of treated end-stage renal failure in the European Union (EU) during the year 1995: report of the European Renal Association Registry and the National Registries. Nephrol Dial Transplant. 1999;14(10):2332-42.

21. Vanholder RC, Ringoir SM. Adequacy of dialysis: a critical analysis. Kidney Int. 1992;42(3):540-58.

22. Eknoyan G, Beck GJ, Cheung AK, et al. Effect of dialysis dose and membrane flux in maintenance hemodialysis. $\mathrm{N}$ Engl J Med. 2002;347(25):2010-9.

23. Valderrabano F. Weekly duration of dialysis treatmen - does it matter for survival? Nephrol Dial Transplant. 1996;11(4):569-72.

24. Charra B, Laurent G, Chazot C, Jean G, Terrat JC, Vanel T. Hemodialysis trends in time, 1989 to 1998 , independent of dose and outcome. Am J Kidney Dis. 1998;32(6 Suppl 4):S63-70.

25. Charra B, Calemard M, Laurent G. Importance of treatment time and blood pressure control in achieving long-term surviva on dialysis. Am J Nephrol. 1996;16(1):35-44.

26. Raj DS, Charra B, Pierratos A, Work J. In search of ideal hemodialysis: is prolonged frequent dialysis the answer? Am J Kidney Dis. 1999;34(4):597-610.

27. Katzarski KS, Charra B, Luik AJ, et al. Fluid state and blood pressure control in patients treated with long and short haemodialysis. Nephrol Dial Transplant. 1999;14(2):369-75.

28. Curtis J. Daily short and nightly nocturnal home hemodialysis: state of the art. Dial Transplant. 2004;33(2):64-71.

29. Smith SC Jr, Blair SN, Bonow RO, et al. AHA/ACC Scientific Statement: AHA/ACC guidelines for preventing heart attack and death in patients with atherosclerotic cardiovascular disease: 2001 update: A statement for healthcare professionals from the American Heart Association and the American College of Cardiology. Circulation. 2001;104(13):1577-9.

30. Tonelli M, Bohm C, Pandeya S, Gill J, Levin A, Kiberd BA. Cardiac risk factors and the use of cardioprotective medications in patients with chronic renal insufficiency. Am J Kidney Dis. 2001;37(3):484-9.

31. Chow FY, Polkinghorne KR, Chadban SJ, Atkins RC, Kerr PG. Cardiovascular risk in dialysis patients: a comparison of risk factors and cardioprotective therapy between 1996 and 2001. Nephrology (Carlton). 2003;8(4):177-83.

32. Berger AK, Duval S, Krumholz HM. Aspirin, beta-blocker, and angiotensin-converting enzyme inhibitor therapy in patients with end-stage renal disease and an acute myocardial infarction. J Am Coll Cardiol. 2003;42(2):201-8.

33. Goldsmith DJ, Covic A. Coronary artery disease in uremia: Etiology, diagnosis, and therapy. Kidney Int. 2001;60(6):2059-78.

34. Ramos EL, Kasiske BL, Alexander SR, et al. The evaluation of candidates for renal transplantation. The current practice of U.S. transplant centers. Transplantation. 1994;57(4):490-7.

35. Mittal SK, Kowalski E, Trenkle J, et al. Prevalence of hypertension in a hemodialysis population. Clin Nephrol. 1999;51(2):77-82.

36. Agarwal R, Nissenson AR, Batlle D, Coyne DW, Trout JR, Warnock DG. Prevalence, treatment, and control of hypertension in chronic hemodialysis patients in the United States. Am J Med. 2003;115(4):291-7.

37. De Lima JJ, Vieira ML, Abensur H, Krieger EM. Baseline blood pressure and other variables influencing survival on haemodialysis of patients without overt cardiovascular disease. Nephrol Dial Transplant. 2001;16(4):793-7.

38. Chazot $\mathrm{C}$, Charra B, Laurent $\mathrm{G}$, et al. Interdialysis blood pressure control by long haemodialysis sessions. Nephrol Dial Transplant. 1995;10(6):831-7.
39 De Lima JJ, Lopes HF, Grupi CJ, et al. Blood pressure influences the occurrence of complex ventricular arrhythmia in hemodialysis patients. Hypertension. 1995;26(6 Pt 2):1200-3.

40. Silberberg JS, Barre PE, Prichard SS, Sniderman AD. Impact of left ventricular hypertrophy on survival in end-stage renal disease. Kidney Int. 1989;36(2):286-90.

41. De Lima JJ, Abensur H, Krieger EM, Pileggi F. Arterial blood pressure and left ventricular hypertrophy in haemodialysis patients. J Hypertens. 1996;14(8):1019-24.

42. Koren MJ, Devereux RB, Casale PN, Savage DD, Laragh JH. Relation of left ventricular mass and geometry to morbidity and mortality in uncomplicated essential hypertension. Ann Intern Med. 1991;114(5):345-52.

43. De Lima JJ, Abensur H, Bernardes-Silva H, Bellotti G, Pileggi F. Role of arterial hypertension in left ventricle hypertrophy in hemodialysis patients: an echocardiographic study. Cardiology. 1992;80(3-4):161-7.

44. Cannella G, Paoletti E, Delfino R, Peloso G, Molinari S, Traverso GB. Regression of left ventricular hypertrophy in hypertensive dialyzed uremic patients on long-term antihypertensive therapy. Kidney Int. 1993;44(4):881-6.

45. Tucker B, Fabbian F, Giles M, Johnston A, Baker LR. Reduction of left ventricular mass index with blood pressure reduction in chronic renal failure. Clin Nephrol. 1999;52(6):377-82.

46. De Lima JJ, Vieira ML, Viviani LF, et al. Long-term impact of renal transplantation on carotid artery properties and on ventricular hypertrophy in end-stage renal failure patients. Nephrol Dial Transplant. 2002;17(4):645-51.

47. Kaysen GA. The microinflammatory state in uremia: causes and potential consequences. J Am Soc Nephrol. 2001;12(7):1549-57.

48. Marcen R, Teruel JL, de la Cal MA, Gamez C. The impact of malnutrition in morbidity and mortality in stable haemodialysis patients. Spanish Cooperative Study of Nutrition in Hemodialysis. Nephrol Dial Transplant. 1997;12(11):2324-31.

49. Aparicio M, Cano N, Chauveau P, et al. Nutritional status of haemodialysis patients: a French national cooperative study French Study Group for Nutrition in Dialysis. Nephrol Dial Transplant. 1999;14(7):1679-86.

50. Avram MM, Bonomini LV, Sreedhara R, Mittman N. Predictive value of nutritional markers (albumin, creatinine, cholesterol, and hematocrit) for patients on dialysis for up to 30 years. Am J Kidney Dis. 1996;28(6):910-7.

51. De Lima JJ, da Fonseca JA, Godoy AD. Baseline variables associated with early death and extended survival on dialysis. Ren Fail. 1998;20(4):581-7.

52. Zimmermann J, Herrlinger S, Pruy A, Metzger T, Wanner C. Inflammation enhances cardiovascular risk and mortality in hemodialysis patients. Kidney Int. 1999;55(2):648-58.

53. Suliman ME, Qureshi AR, Barany P, et al. Hyperhomocysteinemia, nutritional status, and cardiovascular disease in hemodialysis patients. Kidney Int. 2000;57(4):1727-35.

Sources of funding: Supported by EJ Zerbini Foundation São Paulo, Brazil.

Conflicts of interest: Not declared.

Date of first submission: February 16, 2005

Last received: December 1, 2005

Accepted: December 30, 2005 


\section{AUTHQR INFRRMATILN}

José Jayme Galvão de Lima, MD. Assistant Professor, Instituto do Coração (InCor), Faculdade de Medicina da Universidade de São Paulo, São Paulo, Brazil.

\section{Address for correspondence:}

José Jayme Galvão de Lima, M.D., PhD

Unidade de Hipertensão - Instituto do Coração (InCor)

Av. Dr. Enéas de Carvalho Aguiar, 44

São Paulo (SP) - Brasil - CEP 05403-000

Tel./Fax. (+55 11) 3069-5048

E-mail: hipjayme@incor.usp.br
Doenças cardiovasculares em pacientes renais crônicos tratados por hemodiálise: abordagem prática

CONTEXTO: A doença cardiovascular é a principal causa de morte em pacientes tratados por hemodiálise crônica. Embora a uremia por si só possa ser considerada um fator de risco cardiovascular, uma proporção significativa de pacientes tratados por diálise morre devido a problemas cardiovasculares não diretamente atribuíveis à uremia. De fato, muitas das alterações cardiovasculares e fatores de risco cardiovascular observados em pacientes renais crônicos são comuns aos que ocorrem na população geral e podem ser controlados por medidas de comprovada eficácia em indivíduos não-doentes renais. A falta de cuidados médicos apropriados durante as fases iniciais da insuficiência renal e os atuais métodos e rotinas empregadas na diálise, por não conseguirem garantir o controle adequado da hipertensão, hipervolemia e da hipertrofia ventricular, em muitos pacientes, contribuem para o aumento da pletora de problemas cardiovasculares. O autor sugere que, em adição à instituição de tratamento adequado e envio precoce aos especialistas, doentes renais crônicos devam ser submetidos a avaliação cardiovascular minuciosa visando o tratamento das alterações cardiovasculares e correção dos fatores de risco baseados nas diretivas estabelecidas para a população geral.

PALAVRAS-CHAVE: Hemodiálise. Insuficiência renal crônica. Doenças cardiovasculares. Risco. Uremia. Diagnóstico. 